Equinoccio. Revista de psicoterapia psicoanalítica, 2(2), julio-diciembre 2021, pp. 137-156.

ISSN: 2730-4833 (papel), 2730-4957 (en línea). DOI: doi.org/10.53693/ERPPA/2.2.8.

\title{
LA CREACIÓN DE UN AUDIOVISUAL COMO MEDIADOR TERAPÉUTICO
} THE CREATION OF AUDIOVISUAL CONTENT AS A THERAPEUTIC MEDIATOR A CRIAÇÃO DE UM MATERIAL AUDIOVISUAL COMO MEDIADOR TERAPÊUTICO

Inés Lezama

Université Lumière Lyon II Lyon, Francia

Correo electrónico: ilezamat@gmail.com ORCID: 0000-0002-1240-3080

Recibido: 15/3/2021 Aceptado: 12/6/2021 


\section{Resumen}

En una asociación que brinda atención médica y psicológica para personas que padecen sufrimientos vinculados a la experiencia del exilio, se propone un dispositivo de intervención que utiliza el audiovisual como objeto mediador para un grupo de adolescentes refugiados en Francia.

Esta nota de investigación se apoya en preguntas sobre las implicaciones de la especificidad de esta clínica en los procesos de transferencia y contratransferencia y en la construcción de un encuadre-dispositivo. A partir de la experiencia clínica, el trabajo da cuenta de la manera en que las particularidades técnicas de la construcción de un dispositivo audiovisual involucran diferentes formas de transferencia que permitirían volver a poner en juego la reflexividad a través de la materialidad del encuadre.

Palabras clave: objeto, creación, imagen visual, exilio.

\section{Abstract}

In an association that provides medical and psychological care for people who suffer from anguish related to the experience of exile, an intervention device that utilizes audiovisual content as a mediating object for a group of refugee teenagers in France is proposed.

This article is supported by questions about the implications of the specificity of this clinic in the transference and countertransference processes and in the construction of a device-frame. Based on clinical experience, it reveals how the technical peculiarities of the construction of an audiovisual device involve different forms of transference that would allow reflexivity to be put back into play through the materiality of the frame.

Keywords: object, creation, visual image, exile.

\section{Resumo}

Em uma associação que presta atendimento médico e psicológico para pessoas que sofrem por causa de experiências do exílio, propõem-se um dispositivo de intervenção que usa um material audiovisual como objeto mediador para um grupo de adolescentes refugiados na França.

Esta pesquisa está apoiada sobre perguntas das implicâncias da especificidade desta clínica nos processos de transferência e contratransferência e na construção de um enquadramento-dispositivo. A partir da experiência clínica, o trabalho aborda a forma em que as especificidades técnicas da construção de um dispositivo audiovisual incluem diferentes formas de transferência que permitiriam colocar em jogo novamente a reflexividade através da materialidade do enquadramento.

Palavras-chave: objeto, criação, imagem visual, exílio. 


\section{INTRODUCCIÓN}

En el presente trabajo propongo comenzar a pensar en una propuesta de abordaje metodológico para la utilización de la creación audiovisual como mediadora en el trabajo con una población de adolescentes refugiados en Francia. Diversas interrogantes surgen sobre la especificidad de esta clínica y sobre la pertinencia de proponerle a un grupo de adolescentes que atraviesan dificultades vinculadas al exilio un dispositivo audiovisual como mediador.

Una migración conlleva una partida, un desarraigo, pasos fronterizos y el proyecto de una llegada con nuevos arraigos. El tema de la migración y el cruce de fronteras visto desde esta perspectiva concierne tanto un recorrido territorial de diferentes espacios, como una articulación de diferentes temporalidades. La cuestión de la precariedad y el exilio me desafía y es entonces cuando me pregunto cuál es el papel del psicólogo y de la práctica psicoanalítica a la hora de afrontar las configuraciones psíquicas inscriptas en estas realidades.

La creación colectiva de un cortometraje de ficción por un grupo de adolescentes que viven en el exilio en Francia sirvió como lugar de despliegue del cuerpo y la sensorialidad, y como espacio de trabajo para la construcción de una narrativa común. Un trabajo de exploración de los procesos psíquicos inherentes a dicho dispositivo fue posible, lo que permitió, al mismo tiempo, reflexionar sobre las especificidades de este encuadre con relación a las modalidades transferenciales particulares que esta clínica suscita. 
Las reflexiones que desarrollo en este texto son resultado del trabajo final de la maestría en Psicología Clínica de la Universidad Lyon II, que finalicé en 2019. En este texto doy a conocer el campo de investigación donde se desarrolla esta práctica y defino una metodología y una postura de trabajo que incluyen la construcción de un encuadre que posibilite el trabajo en grupo con el mediador mencionado. Con el soporte de ciertos marcos teóricos, desarrollo una reflexión articulada con la experiencia clínica, con el objetivo de explorar las particularidades de esta mediación audiovisual.

\section{CONSTRUCCIÓN DEL DISPOSITIVO, SU ENCUADRE Y SUS INVARIANTES}

El dispositivo tuvo lugar en una asociación francesa de profesionales voluntarios que trabaja acogiendo, desde hace cuarenta años, a personas que viven la experiencia del exilio, provenientes de países de Magreb y África subsahariana. La mayoría de ellos ha sufrido formas violentas de represión y se enfrentan a la inseguridad social en el país de acogida, así como a formas de discriminación ligadas a su origen, color de piel, religión, estatus administrativo y lengua. El equipo de psicólogos recibe sujetos con sufrimientos ligados a pérdidas, duelos y violencia cruel ejercida sobre el cuerpo y sobre la mente. Esta clínica interroga y toca cuestiones de la memoria y las vivencias de unos que se convierten en fantasmas para otros, así como para la disciplina, cuestionando los fundamentos del pensamiento y la práctica psicoanalítica. ¿Qué lugar tiene un psicólogo ante la exclusión social, ante los problemas geopolíticos, ante la extrema precariedad? ¿A qué podemos recurrir de nuestra historia y nuestras bases teóricas para pensar sobre estos temas que nos abruman? 
Los terapeutas que trabajan con exiliados expresan generalmente sentirse desposeídos de los límites esenciales de sus prácticas (Wolmark, 2017). El desafío, entonces, se centra en cómo podemos, en nuestra disciplina, encontrar seguridad para no caer en una práctica que pasa rápidamente a la acción y la sustitución de la escucha por la caridad, para poder pensar en lo que nos debe ocupar, esto es, la realidad psíquica. Cómo poder pensar y trabajar la influencia de la realidad externa sobre la subjetividad, cómo restablecer una fiabilidad en el psicoanálisis y creer en nuestra palabra para poder posicionarnos y pensar en la clínica con personas que también experimentan violencia institucional y ven puesta en cuestión su palabra. Podríamos pensar que es el restablecimiento de la confianza en la relación con el otro lo que será la base del encuentro y la necesidad fundamental para el desarrollo de cualquier intervención. A esto se suma un trabajo inscripto en el marco de una institución que garantice la posibilidad de este encuentro para brindar las condiciones de seguridad que permitan a los profesionales reflexionar sobre las dinámicas transferenciales y contratransferenciales que ahí se despliegan.

El taller de creación audiovisual parece poner a prueba varias de las reglas tradicionales del encuadre analítico, en tanto el dispositivo se coloca en particular oposición a las reglas de restricción del polo perceptivo y motor. Así como el cine no se ocupa de una imagen fija, el encuadre propuesto se caracteriza por una importante dimensión de movimiento, de puesta en escena del cuerpo y del uso de la imagen y de la percepción visual.

Resulta necesario, entonces, para discernir los movimientos del grupo y las dinámicas específicas de los participantes, plantear y circunscribir las invariantes del encuadre del dispositivo audiovisual propuesto. El taller se ofreció para un máximo de seis participantes y se realizó una vez a la semana, todos los sábados a las diez de la mañana, durante dos horas, en un ciclo de diez sesiones. El grupo cerrado que participó del taller 
estuvo integrado por cuatro adolescentes de entre 16 y 18 años. Los encuentros fueron conducidos por un alumno del máster en Audiovisual de la Universidad de Lyon II y por mí, como psicóloga practicante en la institución, en el marco de mi segundo año de maestría en dicha universidad.

La propuesta de este taller se centró en la tarea común de crear juntos un cortometraje de ficción. Para trabajar hacia este objetivo, propusimos algunos pasos, que partieron del desarrollo general de una producción audiovisual: discusión de ideas para la creación de la historia, redacción del guion, dirección y rodaje, edición y visualización de la película. El grupo recorrió estas etapas como y cuando quiso y necesitó, trabajando a partir de ideas individuales y colectivas que surgieran espontáneamente en el grupo. Es decir, los pasos no se siguieron de forma lineal, sino que se produjeron varios movimientos entre ellos de acuerdo con las asociaciones de los participantes.

Existe también una realidad material del dispositivo, que es el equipamiento técnico cinematográfico puesto a disposición de los participantes: una cámara digital, un trípode y un grabador de sonido con auriculares, computadora y proyector. En este contexto, tratamos, principalmente, de dejar que los participantes utilizaran como mejor les pareciera todo el material que pusimos a su disposición. Eligieron desde dónde ubicarse en cada etapa de la creación, la forma de rodaje, el equipamiento, la ubicación de la cámara, la iluminación, la disposición de los personajes en la puesta en escena y la forma de estar en el escenario. Asimismo, posteriormente, al editar eligieron las imágenes, el orden de las escenas, la música y los sonidos. Este proceso dio lugar, en la relación intersubjetiva del grupo, a una creación audiovisual compartida, compuesta por un guion y su puesta en escena filmada que, tras su edición, tuvo una duración de diez minutos.

A partir de esta experiencia, se podría formular que trabajamos en la expectativa del encuentro semanal y en los márgenes de la estructura 
en etapas específicas de creación audiovisual, moviéndonos entre las diferentes etapas y haciendo uso libre de los diferentes medios. Este marco permite, entonces, adaptarse al ritmo de los sujetos en la creación, observar las cadenas asociativas grupales y abrirse también al campo de la asociatividad gesto-mimo-postura, lo que permitiría estudiar el trabajo de simbolización en los diferentes niveles que el dispositivo habilita.

La distinción hecha por Roussillon (2012) de las tres funciones de un dispositivo es también un recurso teórico útil en la construcción y la reflexión sobre el mencionado encuadre. El autor define una función fórica (de contención), una función semafórica (de lugar productor de signo) y una función metafórica (de transformación, puesta en escena y búsqueda de sentido). Estas tres funciones o tres etapas del dispositivo clínico tienen como objetivo guiar el encuentro y se relacionan con el rol y la construcción de nuestro posicionamiento.

Es necesario, por último, mencionar que la creación de una obra audiovisual tiene la particularidad, en la mayoría de los casos, de ser una actividad grupal. Por este motivo, el trabajo se apoyó en algunos desarrollos sobre las dinámicas de grupo, considerando las cuestiones transferenciales específicas (Kaës, 1976).

Milner (1998), en sus desarrollos sobre el medio maleable, distingue dos modalidades específicas de simbolización en los dispositivos de mediación terapéutica: la simbolización de la materialidad del objeto mediador y la simbolización en los vínculos transferenciales con los terapeutas y el grupo. Las transferencias multilaterales se difractan sobre los objetos predispuestos a recibirlos: clínicos, miembros del grupo y, por supuesto, en este caso, el objeto mediador. En suma, se podría asumir que las peculiaridades de lo que organiza el encuentro y la actividad audiovisual sirven de encuadre y determinan la especificidad de los procesos de simbolización que operan en este dispositivo. 


\section{ALGUNAS CONSIDERACIONES SOBRE LA MIGRACIÓN}

El tema del exilio, la migración y el asilo ha sido objeto de muchos nombres y categorizaciones. En este trabajo opto por pensar en la migración como una experiencia subjetiva y por considerar sus diferentes temporalidades. Esto quiere decir que el sujeto no es un sujeto en perpetua migración, en infinito deambular, sino que este recorrido implica el despliegue de los recursos subjetivos y colectivos movilizados por personas con un proyecto de reconstrucción de sus condiciones de vida (Akoka, 2018). Adhiero también a la perspectiva de Tassin (2017), quien expresa que migrar no significa solamente una partida forzada del país de origen, sino la posibilidad de inventar una nueva relación con la identidad, la comunidad y un territorio nuevo.

Con motivo del exilio, los fundamentos primarios del sujeto serán movilizados ampliamente y el reconocimiento del otro ocupará un lugar fundamental para los sujetos que buscan donde instalarse (Pestre, 2015). La noción de refugiado toca lo infantil. Recién llegado, el refugiado encarna la figura absoluta del extranjero que busca la hospitalidad de una nueva comunidad política (Fiala, 2018). Su supervivencia depende, por tanto, de otros que opten por restaurar o no un estatus legal y una protección que ya no tiene (Lhuilier y Pestre, 2018). El refugiado vive en el refugio en una doble relación, por ser un lugar potencialmente reconstituyente, pero a la vez rechazante e incluso mortificante. La experiencia del exilio puede amplificar las experiencias de separaciones, pérdidas y dolor, al mismo tiempo que posibilita un posible renacimiento (Laffite, 1999). La precariedad y la incertidumbre que experimentan la mayoría de los refugiados con respecto a su futuro legal encierran un fuerte potencial traumático que lleva a desarrollar estrategias de supervivencia acompañadas de la producción de nuevas defensas (Pestre, 2010). 
Los psicólogos que se enfrentan a esta población están particularmente expuestos a las dificultades de una práctica que se ubica en la intersección de las clínicas del trauma y el campo social. Si la realidad de la política influye en la vida psicológica del refugiado, también tiene efectos sobre el profesional y sobre la relación transferencial. Las herramientas teóricas y clínicas que permiten el acceso a un soporte sólido a menudo parecen insuficientes en estos casos. Como lo expresa Pestre (2010), el psicoterapeuta muchas veces se siente llamado a tomar una posición extremadamente activa de entrega de respuestas, consejos y soluciones materiales, porque adoptar una actitud silenciosa remitiría a una atmósfera de lo inquietante y de muerte.

Por otro lado, el extranjero genera un doble movimiento de inquietud, terror y atracción. En esta inquietante extrañeza (Freud, 1976) hay efectivamente algo reprimido que vuelve y genera angustia y sentimientos violentos, que en ocasiones conducen a que el clínico tenga sentimientos de aniquilación. Aquello que toca lo desconocido, al igual que el inconsciente, irrumpe en lugares inesperados. El recién llegado, por tanto, puede ser percibido como un huésped parasitario abusivo, y esto sucede, quizás, porque trae consigo experiencias muy cercanas a la muerte, el inconsciente de la cultura. Estos elementos mencionados sobre la práctica clínica con esta población vienen a aportar posibles líneas para pensar la postura del practicante, la construcción de un encuadre terapéutico y las especificidades de los movimientos transferenciales.

\section{OBJETOS MEDIADORES EN LAS CLINICAS DE LO EXTREMO}

El término clínicas de lo extremo es propuesto por Bettelheim en 1960, durante su experiencia en campos de concentración. Se utiliza hoy en 
día para designar las patologías narcisístico-identitarias de personas con impedimentos en los procesos de simbolización. Según Brun (2012), los dispositivos terapéuticos con un mediador resultarían útiles para las situaciones límite de subjetividad o extremos clínicos.

Pintura, música o plástica son ejemplos de las prácticas de mediación terapéutica más clásicas especialmente utilizadas en psicosis y clínicas infantiles. Estas permiten a los pacientes realizar un trabajo figurativo desde el registro sensorial (Milner, 1998). Los desarrollos de Brun (2005) en este campo han permitido estudiar que, en las psicoterapias psicoanalíticas, esta manipulación del medio está ligada a la dinámica transferencial y que es sobre la asociatividad particular del lenguaje corporal y el acto que el clínico centra su atención.

Las características sensoriales del medio maleable (Milner, 1998) desencadenan un proceso de reactivación de experiencias somato-psíquicas no pensables, a veces del tipo de agonías primitivas, descritas por Winnicott (1989). El encuentro con el objeto mediador en el espacio terapéutico permite transformar la sensación alucinada (Brun, 2012) o los significantes formales (Anzieu, 1987) en una forma perceptiva figurable y transformable. El objeto mediador se convierte en un atractor sensorial y en el soporte de la transferencia, al enfocar y articular los vínculos de transferencia-contratransferencia. En este proceso, las sensaciones, experiencias primitivas no simbolizadas de naturaleza sensorio-afectivo-motora, que Brun y Roussillon (2014) denominan formas primarias de simbolización, gradualmente se transformarán en figuraciones escénicas (Aulagnier, 1986) y en mensajes significativos con valor narrativo-expresivo. 


\section{CREACIÓN AUDIOVISUAL Y REFLEXIVIDAD}

Dirijo mis reflexiones hacia la comprensión de la relación entre la materialidad del encuadre y los procesos psíquicos involucrados en el dispositivo. Una primera hipótesis a esbozar podría ser que las particularidades técnicas de la construcción de un dispositivo audiovisual implicarían, a partir de la materialidad del encuadre, diferentes formas de transferencia que permitirían poner en juego aspectos de la reflexividad.

En uno de los primeros encuentros, proponemos realizar una escena de diálogo de ficción frente a la cámara. Drissa, uno de los participantes, preparado para iniciar la escena, en el momento en que se prende la cámara decide presentarse y contar en forma de testimonio su recorrido desde Senegal hasta Francia, con diversos episodios violentos y la desaparición de su hermano en el camino. El contenido de este testimonio y la realidad de la historia nos ponen en dificultades y nos hacen sentir faltos de herramientas y experiencia para darle a este joven una respuesta elaborada. El concepto de despojo de Wolmark (2017) resulta útil para definir el sentimiento que enfrentamos ante esta transferencia tan masiva que nos afecta.

El testigo describe otro supuesto garante, hechos extraordinarios en los que generalmente ha estado involucrado y que forman parte de una dimensión social e histórica (Rey, 2010). Desde esta perspectiva, la historia se convierte en una producción que se puede compartir en intercambios. Con relación a la situación clínica presentada, podemos preguntarnos: ¿a qué responde esta urgencia de contar los hechos frente a una cámara, rodeados por el grupo?, ¿es este modo de narración en forma de testimonio un punto de partida y el juego de ficción una etapa posterior?

El análisis de la posición de inseguridad por el equipo frente a esta situación nos lleva a reformular el encuadre. Nos apoyamos, con este fin, 
en el concepto de Roussillon (2007) de necesidad de seguridad, que indica que el yo necesita vivir en un entorno con suficientes constantes, leyes relativamente fijas y referentes predecibles, es decir, situaciones que no presenten demasiada extrañeza. Es necesario restablecer las reglas y los límites del dispositivo como primer paso para construir una estabilidad suficiente. Por tanto, proponemos una instancia de creación que reúna el interés explícito de los jóvenes por compartir su historia, pero tomando en cuenta la consigna fundamental de pasar por la ficción. Las nuevas limitaciones propuestas en este encuadre son parte de un trabajo, como lo expresa Ciccone (2001), de «reconstrucción de los contenedores antes de trabajar en los contenidos» (p. 94). ${ }^{1}$ Para Winnicott (1971), la creatividad puede expresarse en un entorno suficientemente bueno y tranquilizador, que les permita a los participantes, en este caso, desprenderse de la realidad del testimonio y aventurarse en una puesta en escena ficticia, sin que esto constituya una amenaza. De esta forma, pasar por la ficción, fingir, se convierte en un consenso intersubjetivo, que simboliza las reglas del juego para que el juego sea posible (Roussillon, 2004). El resultado es un rico trabajo de construcción de la narrativa del cortometraje a partir del juego de ida y vuelta entre escribir, filmar y ver la historia.

Otro punto de posible exploración sería el de la materialidad del medio como soporte para la exploración sensorial de la experiencia. La producción de la obra filmada permite reunir a los jóvenes en función de lo que eligen: ocuparse del sonido, de la toma de imágenes, de la edición o de la experiencia de la puesta en escena frente a la cámara. Los participantes deciden qué papel tomar, el encuadre de la toma a filmar, la disposición de los equipos, dónde se paran delante y detrás de la cámara, el espacio donde desplegarán la escena.

1 Tanto la traducción de este fragmento como la de los demás textos citados son mías. 
La detección de los cuerpos por los equipos técnicos, que escuchan, ven y registran, permite plantear la hipótesis de que esto contribuiría, como soporte, a la construcción de la imagen de sí mismo. Sabemos que los traumas ligados en su origen al fracaso de la reflexividad afectan el trabajo de vinculación-diferenciación y la relación con uno mismo, al difuminar el espejo interno necesario para la reflexividad. «El sujeto ya no se percibe o se percibe mal, ya no puede verse a sí mismo o se ve a sí mismo mal, ya no puede oírse o se oye mal, y esto en toda la polisemia de los términos» (Roussillon, 2007, p. 26).

El encuadre del dispositivo marcaría, así, la obligación de coconstruir una imagen de uno mismo a través de la cohesión de los sentidos y al formar un grupo gracias a este ensamblaje de roles. El juego de comodalizar todas las sensaciones captadas por los diferentes equipos permite transformar estas impresiones sensoriales en imágenes e historias, que el grupo puede apropiarse en un proceso de reflexividad. El grupo se revela a sí mismo como un espejo de aumento, al tiempo que ofrece a través del vínculo un apoyo narcisista suficiente, que contribuye al reconocimiento. El espejo del otro y las palabras intercambiadas en el grupo encarnan la posibilidad de un vínculo, ayudan a construir la pertenencia simbólica a una comunidad acogedora y alivian las angustias de la fragmentación y la pérdida de identidad. El desarrollo paulatino del sentimiento de pertenencia y de la dimensión de contención del grupo y el entorno lleva a que este sea un objeto que se puede investir, representar, pensar. El grupo, con nosotros, facilitadores, incluidos y con el medio como objeto de contención y protección, brinda un espacio que promueve la percepción común de las cosas y brinda apoyo para sustentar pensamientos y recuerdos dolorosos. 


\section{DISPOSITIVO AUDIOVISUAL Y SU DIMENSIÓN NARRATIVA}

Siguiendo adelante con esta línea de pensamiento, podríamos explorar una segunda hipótesis: la simbolización específica de un dispositivo audiovisual para adolescentes proviene de un posible entrelazamiento de diferentes formas de lenguaje (verbal, gesto-mimo-postural, visual). Tales formas de simbolización involucradas permitirían la construcción de una narrativa. Una historia, un nuevo lenguaje fabricado, se construiría a partir de la coreografía de interacciones que implican el ir y venir entre la escritura compartida, la puesta en escena grabada, la visualización y la reanudación de la escritura. Estas modalidades específicas del dispositivo propuesto, la sincronización de ritmos y la asociatividad de los participantes contarían una historia tanto individual como grupal. En otras palabras, deseo explorar la forma en que esta asociatividad grupal, en torno a la creación y el trabajo de sincronización de los miembros, se organiza desde un punto de vista narrativo, que lleva no solo un mensaje intersubjetivo, sino también una dimensión simbolizante de la problemática de estos adolescentes en el contexto de su proyecto migratorio.

Al observar el producto final de todas las escenas de la película ya filmadas por el grupo, encontramos que es muy difícil comprender el relato. $\mathrm{El}$ cruce de fronteras entre las distintas épocas de la historia parece romper, incluso disolver, cualquier hilo narrativo. Esta característica de determinadas obras de arte es explorada por Didi-Huberman (2002), quien la describe como «un nudo de tiempo difícil de descifrar, porque hay una constante intersección de movimientos evolutivos y movimientos que resisten la evolución» (p. 53). Esto sugiere que la especificidad del juego de imágenes y percepciones sensoriales toma forma a través de este trabajo y resulta en un modo de procesamiento similar al lenguaje de los sueños. Podría plantearse la interrogante de si el carácter borroso y confuso de 
las imágenes de la historia expresaría algo sobre los efectos de esta experiencia en la psique. Estas imágenes borrosas, este paso indefinido entre un tiempo y otro, vendría a configurar lo que Sausse (2009) define como lo indecible, el mundo de los objetos parciales, los cuerpos fragmentados, el espacio-tiempo disuelto, el rizoma de los afectos, marcado por modulaciones de puntos de vista, grietas y desfasajes en los modos narrativos.

Si continuamos con este razonamiento, se podría pensar que esta creación colectiva muestra la oscilación que existe entre los diversos espacios y temporalidades a las que se enfrentan estos jóvenes. La decisión de hablar aquí de la adolescencia no es anodina. Hablar de la adolescencia y sus emociones nos hace pensar que la emoción es también en sí misma un movimiento y que debemos considerar no solo las vivencias, muchas veces inéditas, que afectan al adolescente, sino también los múltiples cambios a los que estas novedades obligan y, en especial, el trabajo psíquico requerido por la actividad pulsional en el momento de la pubertad (Marty, 2010). Esto, puesto en el contexto de la migración y las vivencias de violencia psicológica y corporal sufridas por estos individuos, nos cuestiona sobre cómo se puede producir en este contexto la integración del cambio corporal en la situación de falta de permanencia del sentimiento de existir. La labilidad de las temporalidades de la película, así como la de los personajes, sugiere la posibilidad de jugar con la incertidumbre de las formas del ser adolescente y los límites cambiantes del cuerpo.

En otras palabras, podría pensarse que la problemática en juego en el espacio psíquico se desarrolla en un espacio transicional intermedio. El encuadre definido previamente por sus especificidades se convierte en un soporte figurativo para el grupo y el sujeto del grupo; un lugar encontrado-creado, al decir de Winnicott (1971). El juego de la puesta en escena grabada opera como un agente de articulación entre identidades, territorios culturales y edades de la vida. En este sentido, esta creación 
encarna en última instancia algo en común entre la adolescencia y la migración, un pasaje.

\section{COCONSTRUCCIÓN DE SENTIDO}

El sujeto de la migración, mientras se desplaza en el espacio o en el tiempo, se enfrenta a pérdidas y duelos: duelos de sentido, entre otros, y quizás al «duelo del sentido que en su mundo de antaño les daba a sus sueños» (Métraux, 2013, p. 350). Los facilitadores experimentamos esta pérdida de sentido de forma contratransferencial. Estas imágenes y estas escenas nos miran y nos tocan al mismo tiempo que las miramos. La exposición a las dificultades cotidianas y su sufrimiento nos asombra. Es difícil encontrar alguna lógica en su viaje tan arriesgado, su desarraigo tan brutal, la exposición y la vulnerabilidad total antes, durante y después del viaje. Quienes intervenimos también nos enfrentamos al duelo de nuestras propias concepciones. Afrontar estas reflexiones nos obliga a dejar de lado nuestras convicciones y nos lleva a intentar elaborar un significado común, crear un mundo compartido, un terreno de integración creativa.

El trabajo resulta, entonces, una cocreación para dotar estas experiencias de significado. A partir de las imágenes visuales creadas, los integrantes están llamados a modificar, continuar, amplificar la historia. La historia se enriquece gradualmente con sentimientos, contradicciones y relaciones. Así, ante la falta de claridad presentada en la película, los participantes sugieren, durante el montaje, agregar música para poder dar un sentido narrativo a las imágenes confusas. Eligen canciones de artistas africanos, canciones con las que se sienten representados a través de sus letras. En esta recuperación de la película y de la historia hay, por lo tanto, un cambio de naturaleza, colores y calidad. El mensaje que 
quieren transmitir toma forma y eso provoca un cierto apaciguamiento en el grupo.

Este enriquecimiento de la historia engloba la idea de la existencia de un interlocutor con el que hablamos a través de la película, aquel que, aunque no responda, reflexiona sobre nuestro discurso y nos permite este ir y venir reflexivo. El arte, la creación, proporciona un contrato narcisista de reconocimiento, así como la posibilidad de compartir elementos de la cultura de pertenencia. Y es esta dimensión cultural la que viene a permitir un espacio de simbolización. Esta instancia habilita a identificar lo que pertenece al adentro-afuera, a mí o al otro, al aquí y ahora o a otro lugar y al pasado (Anzieu, 1985). Mirar la escena desde afuera y discutirla en grupo permite contextualizar su contenido y los sentimientos que evoca, posibilitar su progresiva historización, para que el sujeto pueda empezar a reidentificarse, a rehabilitar el propio tiempo y a empezar a inscribirlo en un relato de subjetivación.

\section{CONCLUSIÓN}

La discusión provocada por el desarrollo de las hipótesis apoyadas en el marco teórico nos permite formular una propuesta de respuesta a la problemática planteada. Podemos pensar que la mediación de la creación audiovisual propiciaría procesos de carácter terapéutico en tanto se convierte en un espacio capaz de recibir elementos brutos de la historia del sujeto. Es a través de este encuentro, a través del acompañamiento de nosotros, los profesionales de la clínica, así como a través del trabajo de desarrollo grupal, que se establecería una puesta en marcha de la reflexividad. De esta manera, el trabajo creativo que se inicia, facilitado por las especificidades del audiovisual en el encuadre especialmente construido para tal fin, permitiría iniciar procesos de subjetivación. 
La clínica del exilio y de los traumatismos ligados a los casos de personas que han vivido una gran violencia activa formas de transferencia que movilizan cuestiones de la angustia y el desamparo, así como cuestiones de identidad, tales como la no pertenencia y la desafiliación. Es por esto que la movilización de los diferentes niveles de comunicación que ofrece el medio, como son el sensoriomotor (por la rítmica que se establece entre los integrantes, la puesta en escena corporal, la elección de la proximidad en el encuadre, los efectos elegidos en el montaje) y el lenguaje verbal (en los momentos de discusión e intercambios sobre las imágenes visualizadas), invitan a desarrollar una asociatividad. Esta asociatividad, tanto verbal como sensoriomotriz, permite la reactivación y la transformación de formas perceptivas no integradas en formas figurativas, transformables y compartibles. El trabajo del mediador de facilitar la transición del registro de sensaciones a emociones produce un mensaje intersubjetivo que podrá adquirir significado en las interrelaciones del grupo. El juego del encuadre y su realidad envolvente hace posible construir un entorno lo suficientemente bueno como para intentar la reconstrucción de una historia a posteriori, colectivamente, en un movimiento que nos permite ver el exilio como una segunda escena. Esta reconstrucción compartida, dialogada, de reconocimiento mutuo, abre una perspectiva de posible afiliación, para entender cómo llegaron aquí y qué asuntos del pasado siguen obedeciendo.

Parecería interesante, en futuras investigaciones, comparar experiencias y profundizar en sus análisis para crear dispositivos que permitan acompañar e identificar los procesos de simbolización o desimbolización en juego. 


\section{REFERENCIAS BIBLIOGRÁFICAS}

Акока, K. (2018). Réfugiés ou migrants? Les enjeux politiques d'une distinction juridique. Nouvelle revue de psychosociologie, 25(1), 15-30. Anzieu, D. (1985). Le Moi-peau. Dunod.

Anzieu, D. (1987). Les signifiants formels et le Moi-Peau. En Les enveloppes psychiques (2. ${ }^{\mathrm{a}}$ ed., pp. 19-41). Dunod.

Aulagnier, P. (1986). Du langage pictural au langage de l'interprète. En Un interprète en quête de sens (pp. 329-358). Ramsay.

BRUn, A. (2005). Historique de la médiation artistique dans la psychothérapie psychanalytique. Psychologie clinique et projective, 11(1), 323-344.

BRun, A. (2012). Les médiations thérapeutiques dans les cliniques de l'extrême. Chimères, 78(3), 63-73.

Brun, A. y Roussillon, R. (eds.). (2014). Les formes primaires de symbolisation. Dunod.

Ciccone, A. (2001). Enveloppe psychique et fonction contenante: modèles et pratiques. Cahiers de psychologie clinique, 17(2), 81-102.

Didi-Huberman, G. (2002). L'image survivante. Histoire de l'art et temps des fantômes selon Aby Warburg. Éditions de Minuit.

FIALA, P. (2018). La famille migr-, champ lexical et affrontements discursifs. En L. Calabrese y M. Veinard, Penser les mots, dire la migration (pp. 145-152). L'Harmattan.

FREUD, S. (1976). L'inquiétante étrangeté: essais de psychanalyse. Gallimard.

KAËs, R. (1976). L'appareil psychique groupal. Dunod.

Lhuilier, D. y Pestre, É. (2018). Introduction. La double face de l'exil. Nouvelle revue de psychosociologie, 25(1), 9-14.

Marty, F. (2010). Adolescence et émotion, une affaire de corps. Enfances \& Psy, 49(4), 40-52.

MÉtraux, J. (2013). De la migration des rêves aux rêves de migration. L'Autre, 14(3), 349-356. 
MiLneR, M. (1998). Le rôle de l'illusion dans la formation du symbole. En B. Chouvier, Matière à symbolisation. Art, création et psychanalyse (pp. 29-59). Delachaux et Niestlé.

Pestre, É. (2010). La vie psychique des réfugiés. Payot et Rivages.

Pestre, É. (2015). Déplacements et subjectivités dans le monde globalisé. Quand le «migrant clandestin» brûle ses attaches premières. L'information psychiatrique, 91(1), 15-20.

REy, A. (2010). Le dictionnaire historique de la langue française. Le Robert.

RoussiLlon, R. (2004). Le jeu et le potentiel. Revue française de psychanalyse, 68(1), 79-94.

RoussiLlon, R. (2007). Le Moi-peau et la réflexivité. Le Carnet PSY, 118(5), 23-27. https://doi.org/10.3917/lcp.118.0023

Roussillon, R. (2012). Manuel de pratique clinique. Elsevier Masson.

TASSIN, É. (2017). Philosophie et politique de la migration. Raison publique, 21, 197-215.

WinnicotT, D. W. (1971). Jeu et Réalité. Gallimard.

WinnicotT, D. W. (1989). La crainte de l'effondrement et autres situations cliniques. Gallimard.

Wolmark, L. (2017). Dépossessions, actes et paroles dans la clinique de l'exil. Rhizome, 63(1), 14-20. 